\title{
ÉTICA, RESPONSABILIDADE SOCIAL E FORMAC̣ÃO DE EDUCADORES
}

\author{
Janete Netto Bassalobre*
}

\begin{abstract}
SEVERINO, Francisca Eleodora Santos (Org.). Ética e formação de professores: política, responsabilidade e autoridade em questão.
\end{abstract} São Paulo: Cortez, 2011, 149 p.

Como o processo educativo ocorre paralelamente ao desenvolvimento contínuo de um sujeito por um lado conectado a comportamentos e atitudes cristalizados na cultura e, por outro, relacionado pela consciência crítica a ideais de liberdade e cidadania, cada educador em formação, mergulhado em incertezas, necessita construir instrumentos próprios que lhe possibilitem subsídios para lidar com o seu universo educacional de maneira verídica e producente, dialogando com as interrogações que se impõem a cada dia, e, ao mesmo tempo, desenvolver uma nova consciência de pertença a um todo integrador das várias nuanças que compõem o tecido social, onde se inclui a educação.

Perante essas incertezas históricas de um mundo singularmente novo, o aspecto ético necessita pautar os fazeres de todos os professores, visando uma tentativa constante de centrar suas análises e interpretações nos dados/aspectos/fatos realmente atuantes encontrados durante a realização de seu trabalho, buscando escapar de uma imagem um tanto fantasiosa que se faz de um universo encantado e perfeito onde deveria ocorrer o processo educativo (por vezes construído intimamente dentro de cada um, talvez na esperança de que se possa efetivamente realizar a fusão entre a realidade e o ideal) e com o qual todos nos defrontamos, algumas vezes permeando a literatura na área da educação.

\footnotetext{
* Mestre em Educação; Professora da Faculdade de Tecnologia Rubens Lara (FATEC - BS); Psicóloga Clínica de linha Junguiana Pós-graduada em Neuropsicobiologia. E-mail: janette@litoral.com.br
} 
A obra organizada pela dra. Francisca Santos Severino, pesquisadora junto à UNIABC do Grupo de Gestão de Processos Educativos, trata das questões relacionadas à ética que permeiam a formação de educadores, objetivando compreender as transformações que vêm ocorrendo nas relações da ética com a prática educativa e respectiva responsabilidade social. A obra apresenta um diálogo entre autores da Sociologia, da Filosofia e da Pedagogia, no sentido de um trabalho que entrelaça a ética e a formação de docentes, norteando o enfoque de questões concernentes à prática educativa e a discussão da identidade do educador frente às novas formas de racionalidade e de produção de conhecimento escolar.

As reflexões entre os autores convergem para uma análise realizada sob a óptica de um processo educativo orientado pela consciência crítica e pelos ideais de liberdade e autonomia. As relações entre os campos da ética, da construção da cidadania e da responsabilidade social e as suas aplicabilidades no universo educacional são discutidas a partir da ideia do nascer de uma outra consciência abrangendo o processo educacional, na qual educação e formação ética se encontrariam obrigatoriamente, visão essa que dialoga fluentemente com outra obra relacionada ao tema aqui proposto - Pós-modernidade, ética e educaşão, na qual Pedro Goergen ${ }^{1}$ insiste na construção de uma nova ética em um projeto educativo que recupere as dimensões perdidas de uma sociedade que se encontra no limiar de uma nova consciência.

Após o prefácio de Pedro Goergen (que vai destacar a importância da educação, da consciência moral no cenário de um mundo globalizado e, ainda, da escola, cujo papel vai muito além da mera transmissão de conhecimentos) e da substanciosa apresentação efetuada pela organizadora da coletânea (que não deixa dúvidas quanto à relevância da obra em questão), compondo o primeiro capítulo - Ética e autoridade em programas de formação de professores: diálogos com Paulo Freire-, temos Gomercindo Ghiggi, da Universidade Federal de Pelotas, que recupera em seu artigo a dimensão ética que Freire construiu na reflexão sobre a formação de professores, a partir de um trabalho desenvolvido junto a turmas de educadores em formação inicial da Faculdade de Educação da UFPel.

O autor, apontando para a historicidade dos conceitos de liberdade, ética, autoridade e prática decente, aborda a produção da ética em Freire como referência para o pensar sobre a formação de professores 
reflexivos e aptos à intervenção social, capazes de reanalisar suas práticas e promover mobilizações necessárias à criação de comportamentos em prol de mudanças na organização social. Reportando-se aos postulados freireanos, Gomercindo retoma a discussão da natureza do trabalho da universidade e da possibilidade da convivência de professores livres, juntamente com a existência da autoridade criadora, onde a ética surgiria como delimitação para a construção de políticas para a formação docente em sintonia com as necessidades das escolas e das comunidades.

O segundo capítulo - As dimensões ética e política na formação docente, assinado por Valdemir Guzzo, da Universidade de Caxias do Sul, resgata a questão da ação docente estar fundamentada na construção da cidadania, por sua vez um dos objetivos básicos da educação. A temática é desenvolvida a partir das colocações de Paulo Freire, sendo a cidadania, dentro da conjuntura do capítulo, entendida como máxima realização do sujeito no contexto social e vivenciada através da participação ativa desse sujeito nas diferentes esferas da vida pública. Dessa maneira, para que possa ocorrer o surgimento de uma escola realmente apta a formar cidadãos efetivos e que atenda às necessidades de diferentes grupos sociais, é necessário que se executem mudanças nos cursos de formação de educadores que, então, dirigirão seus atos balizados a partir de uma consciência política e ética de sua prática. É na base da formação docente que os futuros professores aprofundam os conhecimentos teóricos e técnicos que os conscientizarão do seu papel no ambiente social e que lhe permitirão analisar criticamente os projetos educacionais no sentido de redescobrir novos caminhos para lidar com os desafios da educação em nossa época.

Cleoni Fernandes, pedagoga e pesquisadora do Programa de Pós-Graduação da PUC do Rio Grande do Sul, é a responsável pelo terceiro capítulo - Formação de professores, ética, solidariedade e cidadania: em busca da bumanidade do bumano. Ela nos oferece uma consideração que engloba tanto a complexidade como a beleza das experiências vividas pelo professor em seu cotidiano, partindo da premissa de que a especificidade da educação reside na sua prática e, consequentemente, necessita fundamentar-se em valores éticos a fim de inserir-se na dimensão ética da existência humana. Segundo a autora, pensar em educação é admitir uma implicação permanente com os atos políticos, sócio-históricos e culturais, uma vez que a educação nos rodeia e está presente onde e como estejamos e a perspectiva é a de 
uma sociedade desumanizada, permeada de injustiças e desigualdades sociais, onde a educação é encarada, no mor das vezes, como "uma linha de produção em série” (p. 62).

Ao refletir sobre questões como "qual a ideia de ciência hoje?"; "para quem e para que o conhecimento?”; “qual o papel da ética?”; "como trabalhar com práticas cidadãs?”, concebe o conhecimento como uma construção coletiva de sujeitos inseridos em um contexto sociocultural (e por isso mesmo diferenciados em cada época) e a universidade como uma instituição edificada em uma perspectiva de mercado cada vez mais excludente, construída nesses embates das contradições de cada época. Assim, o conhecimento transforma-se em um bem de "[...] utilidade imediata, ascensão social e mercadoria [...]" (p. 64) e, por sua vez, a concepção de ciência mantém-se marcada pela certeza e verdade pronta, presidindo o exercício pedagógico e curricular: continua-se trabalhando com o conhecimento do passado e não com os desafios do presente, ficando a prática limitada a execução de tarefas e ações sem reflexão. Sob o fio condutor de Freire, Cleoni destaca todo o tempo o conceito de educação como práxis histórico-política, sociocultural e existencial onde a teoria e a prática estão em perpétuo movimento dialético; o conhecimento surge como construção histórica; as diferenças se constituem como categorias de conteúdo ético e cultural e o contexto cultural como fonte para a edificação da consciência crítica.

A organizadora da coletânea, Francisca Severino, socióloga e doutora em Comunicações pela USP, no capítulo quatro - Ética e responsabilidade social no ensino superior, remete-nos a uma diferenciação nas abordagens filosófica e sociológica ao refletir sobre o tema: amparada nas contribuições de Marx, Weber e Durkheim, acentua a necessidade de se pensar a educação ética baseada nas mudanças sociais - rever valores superados ainda remanescentes no cenário educativo é necessário se pretendemos pensar a ética considerando suas determinações históricas e sociais.

Utilizando como alavanca para suas reflexões o depoimento de uma mãe humilde e favelada (extraído de um trabalhado de pesquisa) a respeito de seu filho de 16 anos (em atrito com a lei e colocado em medida socioeducativa), que se recusa a frequentar a escola pela razão de nela não se encontrar, Francisca Severino transita pelo cenário neoliberalista que se embaralha nas relações escolares, enevoando antigos valores que insistem em se manter metamorfoseados com novas roupagens, impedindo assim 
o surgimento de novos, que precisam surgir para ocasionar as mudanças efetivas necessárias no processo educacional. A autora evidencia como o "desencantamento do mundo" (p. 84) amplia as questões relativas aos valores que delimitam a ética do agir humano para além da filosofia, conectando-os às questões econômicas, discutindo a ética enquanto responsabilidade social, aspecto que deve estar presente no processo pedagógico da formação de educadores.

Em seguida, Pedro Goergen assina o quinto capítulo da obra - Educação para a responsabilidade social: pontos de partida para uma nova ética. Nesse espaço, o autor vai ratificar o entendimento de escola como formadora de cidadãos, sublinhando as possibilidades promissoras que podem sustentar uma fundamentação ética para a sociedade contemporânea, embora uma análise das interrelações das atividades humanas em um cenário permeado por transformações globalizadas possa demonstrar uma desesperança a esse respeito, haja vista, por exemplo, toda a preocupação com a atual desconstrução de valores e a relevância hedonista que prioriza demasiadamente os interesses individuais em detrimento da empatia e da solidariedade.

Pedro analisa a questão estrutural da construção da identidade através da socialização, presente obrigatoriamente no processo de desenvolvimento de cada um, permeada pelo fato de que vivermos em um mundo globalizado, célere e pleno de mudanças (o que nos torna inseguros e desorientados, consequentemente), pontuando a existência de um código ético ambivalente, uma vez que sociedade e homem são sempre imperfeitos e, da mesma forma, repletos de ambiguidades e contradições. Entretanto, apesar de admitir a predominância atual da consciência do eu substituindo a consciência coletiva, afirma que esses fatos não invalidam o projeto de construção de uma sociedade melhor e de uma identidade baseadas em princípios éticos dissociados das circunstâncias meramente alienantes e utilitaristas, vinculadas a um turbilhão de mudanças e transformações que reforçam o materialismo hedonista, onde o próprio ambiente exige que as preocupações ideológicas cedam espaço às apreensões ligadas à própria sobrevivência.

Finalizando os trabalhos, o livre-docente em Filosofia da Educação, professor Antonio Joaquim Severino, assina o capítulo seis - Formação e atuação dos professores: dos seus fundamentos éticos. Nele, inicialmente, acentua a necessidade ética no exercício da docência, uma vez que a educação é 
um fazer intimamente ligado à existência do outro e alcança diretamente os alunos, por sua vez pessoas menos resistentes à intervenção advinda da figura dos educadores e, aponta, nessa direção, a indispensabilidade de preencher a formação dos docentes com essa sensibilidade ética, através de uma

[...] mediação pedagógica para [o] desenvolvimento de nossas sensibilidades às diferentes gamas de valores que qualificam nossas ações", mediação essa amparada por um constante "exercício de reflexão sistematicamente conduzido [...] (p. 131).

Destacando o conceito de formação enquanto condição de plena humanidade dos sujeitos - o que subsume a questão dos valores (em especial os éticos e políticos) -, realiza uma síntese abarcando tanto o sentido que atribui à educação quanto o papel que a ética ocupa no processo educativo, identificando esses valores como referências basilares e alicerçadoras para o agir intencionado dos seres humanos, ressaltando o fato de que, uma vez que a educação tem como um de seus deveres transmutar o sujeito em indivíduo autônomo, torna-se premente a necessidade de levá-lo a refletir e reavaliar seus valores morais, a fim de se apoderar de posturas éticas em seu agir. Lembra, ainda, que o envolvimento pessoal de todo educador e sua sensibilidade ética estão articulados a um compromisso com o destino da humanidade na construção de uma sociedade melhor e mais equitativa.

Enfim, envolvidos pelas considerações do professor Severino e dos outros colaboradores dessa obra, retomamos a consciência de que o movimento do mundo em contínuo processo implica no reconhecimento do homem como autor de sua própria história, e que é fato que a educação insere-se nessa marcha como mediadora entre o indivíduo e a sociedade, onde cada um em particular realiza em si o universal. Sabemos, também, que não é apenas através da educação que se dará a tão esperada transformação da sociedade, contudo sua importância advém do fato de que produz intencionalmente em cada indivíduo a humanidade que é produzida coletivamente pelo conjunto dos homens.

Dessa maneira, a obra resenhada, que reflete uma discussão bastante presente no imaginário social, apresenta-se como uma importante contribuição voltada àqueles interessados em pensar as relações da ética e da contemporaneidade com a área educacional, mais especificamente no 
sentido da formação de educadores, da mesma forma que na ressignificação do entendimento de uma escola formadora de cidadanias emancipatórias em seus vários aspectos, como também já o desejava Paulo Freire. O livro recebe uma profunda atenção dentro da perspectiva de reconstrução de posturas, proporcionando possibilidades de reflexão e discussão acerca da ética na formação de professores atrelada à questão da responsabilidade social, uma vez que ocorre, na atualidade, uma forte tentativa de resgate de valores supostamente perdidos pela sociedade que, na verdade, são responsáveis pela construção da emancipação de todos.

Só assim uma escola pode manter-se viva e recriar a cada dia o significado de incluir, formar e "cidadanizar", que é participar juntamente com todos na realização das cidadanias, principalmente daqueles indivíduos marcados pelo estigma da desigualdade em um país onde as classes populares são reconhecidas injustamente como ameaçadoras pela feiura da miséria que ostentam. Ela deve concentrar sua atenção nas medidas que pode realmente efetivar, em nome das teorias que assume e defende. As incertezas originadas dessa realidade e o saber lidar com elas certamente fazem parte do aprendizado.

Portanto, o livro apresenta-se como uma válida contribuição no âmbito da educação, voltada não só aos profissionais da área educacional dedicados à formação dos futuros educadores mas, também, aos trabalhadores sociais de muitos segmentos da sociedade, uma vez que essa vinculação de educação, ética e responsabilidade social merece a atenção de pensadores e cientistas das mais diversas áreas.

\section{NOTAS}

${ }^{1}$ GOERGEN, P. Pós-modernidade, ética e educação. 2. ed. Campinas: Autores Associados, 2005.

Recebido: 25/09/2012

Aprovado: 05/12/2012

Contato:
Faculdade de Tecnologia Rubens Lara
Curso de licenciatura para formação de professores do ensino técnico
Av. Bartolomeu de Gusmão, 110
CEP 11045-908
Santos, SP
Brasil

